\title{
Mediastinal paraganglioma: Utility of preoperative cardiac magnetic resonance imaging
}

\author{
Davinder S. Jassal, MD, FRCPC, ${ }^{a, b}$ Umaima Fatima, MD, ${ }^{c}$ Amar Thakrar, MD, ${ }^{d}$ Tomas G. Neilan, MD, ${ }^{a}$ \\ Norma Rodriguez, MD, ${ }^{\mathrm{e}}$ Andrew Rosenberg, MD, ${ }^{\mathrm{e}}$ and Godtfred Holmvang, MD, ${ }^{\mathrm{C}}$ Boston, Massachusetts, Winnipeg, \\ Manitoba, Canada, and Saskatoon, Saskatchewan, Canada
}

$\mathrm{P}$ aragangliomas are tumors composed of neuroendocrine tissue that arise from chromaffin cells of the autonomic nervous system. ${ }^{1}$ Mediastinal paragangliomas originate from the paraganglia around the cardiac plexus or from the aorticosympathetic chain in the costovertebral sulcus. ${ }^{2}$ Symptoms from mediastinal paragangliomas are related to pressure and compression of adjacent structures. Although the first symptoms are constitutional, cardiovascular symptoms, including chest discomfort, dyspnea, cough, and stridor, have been reported. ${ }^{2,3}$ The diagnosis and management of mediastinal paragangliomas are strongly dependent on noninvasive imaging modalities, including echocardiography, multidetector computed tomography, and $\mathrm{I}^{131}$ iodine-131-meta-iodobenzylguanidine scans. However, cardiac magnetic resonance (CMR) is becoming the imaging modality of choice, with the advantages of multiplanar imaging, tissue characterization of the tumor mass, and assessment of vascularity of the tumor.

\section{Clinical Summary}

A 49-year-old man with a history of bilateral carotid body tumors excised in 1998 and 1999 presented with a 6-month history of fatigue, exertional dyspnea, and anterior chest discomfort radiating to the left arm on minimal exertion. The cardiorespiratory examination was unremarkable. A stress methoxyisobutyl isonitrile revealed no evidence of ischemia but revealed a mediastinal mass with uptake of technetium in the aortopulmonary window. CMR imaging was performed to further delineate the mass. The mediastinal mass measured $7.4 \times 6.2 \times 4.3 \mathrm{~cm}$ in dimension and was located beneath the ascending aorta, compressing the left atrium, left main stem bronchus, superior vena cava, right pulmonary artery, and posterior portion of the aorta (Figure 1, A). It had

\footnotetext{
From the Cardiac Ultrasound Laboratory, Division of Cardiology, ${ }^{\mathrm{a}}$ the Department of Radiology, ${ }^{\mathrm{c}}$ and the Department of Pathology, ${ }^{\mathrm{e}}$ Massachusetts General Hospital, Boston, Massachusetts; the Institute of Cardiovascular Sciences, ${ }^{\text {b }}$ Cardiology Division, Department of Cardiac Sciences, St Boniface General Hospital, Winnipeg, Manitoba, Canada; and the Department of Internal Medicine, ${ }^{\mathrm{d}}$ Royal University Hospital, Saskatoon, Saskatchewan, Canada.

Received for publication June 3, 2006; revisions received June 19, 2006; accepted for publication June 29, 2006.

Address for reprints: Davinder S. Jassal, MD, FACC, FRCP(C), Institute of Cardiovascular Sciences, Cardiology Division, Department of Cardiac Sciences, St Boniface General Hospital, Winnipeg, Manitoba, Canada, R2H 2A6 (Tel: 204-237-2023; E-mail: djassal@shaw.ca).

J Thorac Cardiovasc Surg 2006;132:976-7

$0022-5223 / \$ 32.00$

Copyright @ 2006 by The American Association for Thoracic Surgery doi:10.1016/j.jtcvs.2006.06.011
}

intermediate signal intensity on T1-weighted imaging and was hyperintense on $\mathrm{T} 2$-weighted and proton density imaging. A volume-rendered 3-dimensional reconstruction cine-magnetic resonance image (MRI) defined the location and extent of the tumor with a number of feeding vessels (Figure 1,B).

During cardiopulmonary bypass, a large vascular tumor was identified beneath the ascending aorta and aortic arch. The tumor was separated from the medial portion of the superior vena cava, the right pulmonary artery, and the posterior portion of the ascending aorta. Small remnants of the tumor were left behind because of excessive bleeding from the increased vascularity of the tumor. The tumor was an irregular, brown-red soft tissue mass surrounded by a thin capsule of tissue measuring $7.0 \mathrm{~cm}$ in greatest dimension (Figure 2, A). The histologic examination of the operative specimen was characteristic of a paraganglioma (Figure 2, B). At 1-year followup, the patient remains asymptomatic, and CMR imaging revealed a $0.5 \times 0.2 \times 0.2-\mathrm{cm}$ remnant of the paraganglioma mass.

\section{Discussion}

Mediastinal paragangliomas are rare, highly vascular tumors that arise from extra-adrenal chromaffin cells. The majority are benign, with malignancy reported in only $5 \%$ to $10 \%$ of cases. ${ }^{2}$ Histologic examination reveals nests of cells, round or ovoid in shape, which are separated by blood vessels. ${ }^{2}$ The vascularity of paragangliomas mandates exact determination of the extent and nature of invasion of the malignancy, which is important for surgical planning.

CMR is valuable in this respect because it characterizes the tumor's location, extent, and interface between the neoplastic tissue and its surrounding structures. In addition to the multiplanar imaging capabilities of CMR, tissue characteristics of the intrathoracic mass, including $\mathrm{T} 1, \mathrm{~T} 2$, proton density, and hyperenhancement after administration of contrast, aids in the differential diagnosis of cardiac tumors. In our case, the paraganglioma was hyperintense in relation to the myocardium on T1-, T2-, and proton density-weighted images, which is suggestive of a malignant lesion. A highly vascular tumor, as suggested by strong hyperenhancement after gadolinium administration and the identification of numerous tumor vessels on cine-MRI, is suggestive of the diagnosis of a mediastinal paraganglioma. Although the use of MRI in the assessment of mediastinal paraganglioma has been previously described, ${ }^{3-5}$ this is the first case report illustrating the utility of CMR, combining cine-MRI, spin and gradient echocardiographic techniques, and hyperenhancement with contrast administration for the comprehensive preoperative evaluation of a mediastinal paraganglioma. Although not performed in our case, follow-up CMR after surgical resection of the neoplasm is useful to determine the response to therapy and adequacy of resection and to identify recurrence. 

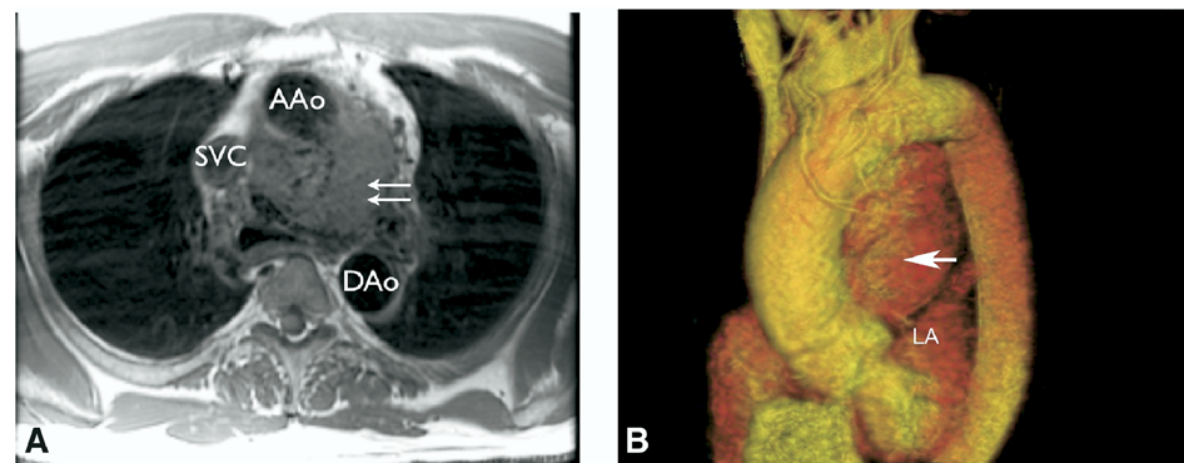

Figure 1. A, A T1-weighted conventional spin echocardiographic image in the axial view demonstrating the mass (double arrow) with intermediate signal compressing the left main stem bronchus, left pulmonary artery and left atrium. $S V C$, Superior vena cava; $A A O$, ascending aorta; DAo, descending aorta. B, A volume-rendered 3-dimensional reconstruction cine MRI defining the location and extent of the tumor (arrow) with a number of feeding vessels. $L A$, Left atrium.
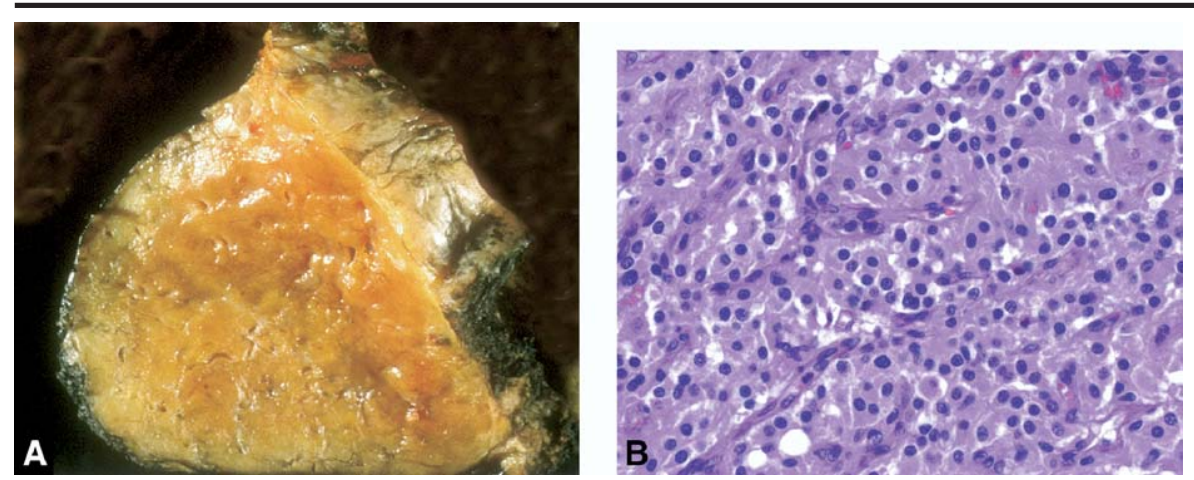

Figure 2. A, Gross image. The tumor measured $7.0 \mathrm{~cm}$ in greatest dimension. It consisted of a homogeneous, red-pink to tan-brown soft tissue mass with a thin capsule $(<0.1 \mathrm{~cm}$ in thickness). B, Light microscopy (high power). The tumor cells have abundant clear-to-granular eosinophilic cytoplasm and uniform round-to-ovoid nuclei with nondistinct cell borders. Some nuclei are enlarged and hyperchromatic.
CMR is rapidly becoming an invaluable tool in the evaluation of cardiac and great vessel tumors, including mediastinal paragangliomas, as evidenced by this case.

\section{References}

1. Sahdev A, Sohaib A, Monson JP, Grossman AB, Chew SL, Reznek RH. CT and MR imaging of unusual locations of extra-adrenal paragangliomas (pheochromocytomas). Eur Radiol. 2005;15:85-92.
2. Mader MT, Poulton TB, White RD. Malignant tumors of the heart and great vessels: MR imaging appearance. Radiographics. 1997; 17:145-53.

3. Flickinger FW, Yuh WT, Behrendt DM. Magnetic resonance imaging of mediastinal paraganglioma. Chest. 1988;94:652-4.

4. Sahin-Akyar G, Erden I, Yagci C, Akyar S, Erekul S. Magnetic resonance imaging findings of a nonfunctional mediastinal paraganglioma with an unusual presentation. Eur Radiol. 1997;7:1114-6.

5. Nwose P, Galbis JM, Okafor O, Torre W. Mediastinal paraganglioma: a case report. Thorac Cardiovasc Surg. 1998;46:376-9. 